\title{
Tardigrades of Fish Creek Provincial Park, Alberta, Canada: A Preliminary Survey
}

\author{
GARY T. GROTHMAN \\ Natural and Mathematical Sciences Area, St. Mary’s University College, Calgary, Alberta T2X 1Z4 Canada; email: gary.grothman \\ @stmu.ab.ca
}

Grothman, Gary T. 2011. Tardigrades of Fish Creek Provincial Park, Alberta, Canada: a preliminary survey. Canadian FieldNaturalist 125(1): 22-26.

Tardigrades are cosmopolitan animals with a patchy distribution record, largely due to the limited collection history for this phylum rather than actual rarity. Most Canadian records are from near coastal areas, with a few notable exceptions, most recently one study of tardigrades in central Alberta. The present study reports the occurrence of 12 species or species groups in Fish Creek Provincial Park in southern Alberta. Eight of these taxa are new records for Alberta, and two (Diphascon (Diphascon) granifer and Echiniscus granulatus) are new records for Canada.

Key Words: Tardigrada, survey, meiofauna, Alberta.

Tardigrades (phylum Tardigrada), also commonly known as water bears, are microscopic invertebrates (normally < $800 \mu \mathrm{m})$ (Kinchin 1994) found in ecosystems from the Arctic and the Antarctic to the tropics, on sandy beaches, the ocean bottom, in shallow ponds, and, most famously, in mosses (Kinchin 1994; McInnes 1994). While all tardigrades in their active state are dependent on a film of water and so may be considered aquatic, for convenience those from non-submerged habitats may be described as terrestrial (Ramazzotti and Maucci 1983).

Their most widely recognized characteristic is remarkable resilience, including an ability to survive long periods without water by entering an anhydrobiotic stage in which they crumple down to resemble a speck of dust, surviving for up to 10 years in this desiccated state before being rehydrated and resuming normal life (Jönsson and Bertolani 2001; Bertolani et al. 2004). They have been shown to resist extremes of heat (Doyère 1842; Rahm 1921) and cold (Becquerel 1950; Hengherr et al. 2009), radiation (May et al. 1964), high pressure, and vacuum (Seki and Toyoshima 1998) - indeed, they are the only animals so far to have been deliberately exposed to the vacuum and radiation of space, which they survived (Jönsson et al. 2008).

Fish Creek Provincial Park $\left(50^{\circ} 55^{\prime} \mathrm{N}, 114^{\circ} 3^{\prime} \mathrm{W}\right)$ is a natural area in Calgary, Alberta, at an elevation of approximately $1048 \mathrm{~m}$ (Figure 1). The area has long, dry, cold but highly variable winters and short, moderately warm summers; the yearly mean temperature is $4.1^{\circ} \mathrm{C}$ and the mean annual precipitation is $412.6 \mathrm{~mm}$ (National Climate Data and Information Archive 2010*). At 1348 ha, Fish Creek Provincial Park is one of Canada's largest urban parks, and it is almost entirely enclosed within the city (Friends of Fish Creek 2010*).

Fish Creek Provincial Park is at the northwestern edge of the Prairie ecozone, and it contains grasslands, Trembling Aspen (Populus tremuloides) woods, ripari- an forest, White Spruce (Picea glauca) forest, and natural and engineered wetlands (Robertson 1991; Friends of Fish Creek 2010*). Trembling Aspens tend to grow at the edge of floodplain terraces, along the tops of north-facing slopes, and in ravines, while riparian vegetation is dominated by Balsam Poplars (Populus balsamifera) and willows (Salix spp.) (Pinel 1980). White Spruce are located on north-facing slopes and floodplains between the Trembling Aspen and riparian vegetation in the western end of the park (Pinel 1980). Grasslands occur on the floodplain and drier southfacing slopes (Pinel 1980).

Only one previous survey of terrestrial tardigrades has been carried out in Alberta (Boeckner and Proctor 2005). Fish Creek Provincial Park is an ideal location in which to begin a more widespread survey. It not only includes a good mixture of ecosystem types, but it also contains both natural and disturbed areas appropriate for longitudinal studies of anthropogenic impacts on tardigrades. Relatively few studies of the colonization of newly altered environments by tardigrades have been performed (Uhía and Briones 2002; Hohberg 2006), so the colonization of the engineered wetlands recently completed in the Park to treat stormwater runoff from the surrounding communities will be of particular interest (Friends of Fish Creek 2009*). In their cryptobiotic state, tardigrades are easily dispersed by passive transport (Nelson et al. 2009); therefore, terrestrial tardigrades should be fairly early colonizers of disturbed areas, particularly areas with erratic periods of moisture and temperature. Truly aquatic tardigrades, which lack a desiccated "tun" stage with its presumed wind-dispersal capacity, are likely to be less easily dispersed (Nelson et al. 2009).

There is a general need for wider surveys of the distribution of this phylum; the majority of the more than 1000 species described have been found in only one region, or even in only a single sampling site (McInnes 


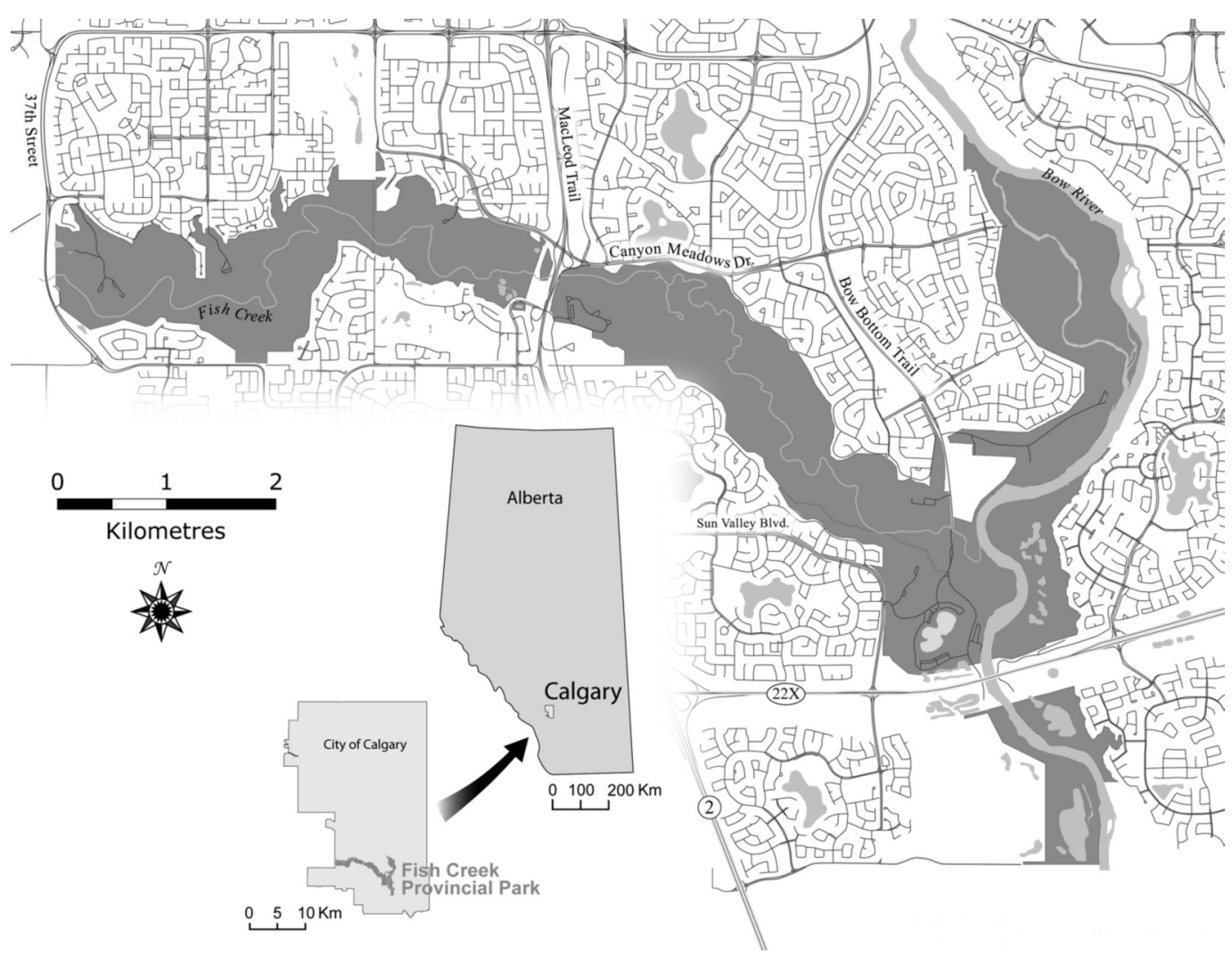

FIgURE 1. Fish Creek Provincial Park, Calgary, Alberta, Canada (Alberta Tourism, Parks and Recreation, Canmore)

1994; Pilato and Binda 2001). This is likely due as much to the patchiness of tardigrade surveys as to any patchiness in tardigrade distribution.

Previous studies that concentrated on or included Canadian tardigrades are usefully summarized in Bateman and Collins (2001), updated by Boeckner et al. (2006). Since the preparation of these two lists, two additional studies have been published (Boeckner and Proctor 2005; Collins 2010). The majority of work has been performed on so-called terrestrial tardigrades, which inhabit mostly moss, lichen, and leaf litter, with only one study, of mountain lakes, including tardigrades of permanent water bodies (Anderson and de Henau 1980).

\section{Methods}

In total, 73 samples were collected, and GPS coordinates and location descriptions were recorded. The sampling and processing procedure of Nelson et al. (2009) was used. Samples of dry moss $(\sim 250 \mathrm{~mL})$, lichen $(\sim 1 \mathrm{~mL})$, and leaf litter $(\sim 250 \mathrm{~mL})$ were collected by hand and stored up to one year, but normally less than two weeks, in paper bags in a sealed specimen cabinet. This procedure will have selected against species with little capacity for anhydrobiotic survival.
Samples of aquatic sediment $(\sim 125 \mathrm{~mL})$ were collected in jars and processed within six hours.

Dry samples were soaked in bottled water (Culligan) for 16-24 hours, agitated, and filtered through stacked sieves $(1.4 \mathrm{~mm}, 75 \mu \mathrm{m}$, and in some cases $45 \mu \mathrm{m})$. The $75 \mu \mathrm{m}$ and $45 \mu \mathrm{m}$ sieves were backwashed, with the collected material immediately fixed in boiling 95\% reagent alcohol. In cases of heavy burden with inorganic matter, a modification of the procedure of Hallas (1975) was followed: samples were allowed to settle for 5 minutes, the precipitate was re-suspended in $50 \%$ sucrose and centrifuged for 5 minutes at 1200 $\times \mathrm{g}$, and then the supernatant was re-filtered through the finest sieve and collected by backwashing with $80 \%$ alcohol. Aquatic samples were briefly stirred and allowed to settle to remove the most dense sediment, and then the liquid was decanted and filtered as above.

Samples were examined with a stereomicroscope at $30 \times$, and specimens were mounted in polyvinyl alcohol (Bioquip 6371A) for observation with a Leica DME compound microscope using brightfield and phase contrast. Specimens were observed immediately in order to record perishable characters such as colour and eyespots, then the specimens allowed to decolourize for two weeks and were re-observed for internal 
TABLE 1. Number of tardigrades, by species in each substrate, recovered from Fish Creek Provincial Park. Abbreviations used: cf. = provisional identification to species; gr. = group of closely related species; sp. = unidentified species of subgenus.

\begin{tabular}{|c|c|c|c|}
\hline & \multicolumn{3}{|c|}{ Substrate } \\
\hline & Moss & Lichen & Leaf litter \\
\hline Number of samples that contained tardigrades & 14 & 9 & 7 \\
\hline (total number of samples in parentheses) & $(29)$ & (12) & (14) \\
\hline Diphascon (Adropion) cf. prorsirostre & & 2 & \\
\hline Diphascon (Diphascon) granifer & & & 3 \\
\hline Diphascon $(D)$ pingue gr. & 4 & & \\
\hline Diphascon (D) sp. & & 1 & \\
\hline Echiniscus granulatus & 1 & & \\
\hline Hypsibius convergens & & & 4 \\
\hline Isohypsibius lunulatus & 25 & & \\
\hline Isohypsibius $\mathrm{cf}$. prosostomus & 40 & & \\
\hline Isohypsibius tuberculatus gr. & & & 2 \\
\hline Macrobiotus cf. harmsworthi & 11 & 1 & \\
\hline Milnesium tardigradum gr. & 10 & 16 & 4 \\
\hline Paramacrobiotus cf. richtersi & 8 & & 5 \\
\hline Ramazzottius oberhaeuseri gr. & 47 & 47 & 3 \\
\hline Unidentified to this level & 141 & 7 & 22 \\
\hline
\end{tabular}

morphology. Permanent mounts of all specimens are stored at St. Mary's University College and are available for review.

Identification of specimens was based primarily on the keys of Ramazzotti and Maucci (1983); Dastych (1988); Nelson et al. (2009); Pilato and Binda (2010). Taxonomy and nomenclature were confirmed with the most recent checklists (Guidetti and Bertolani 2005; Degma and Guidetti 2007; Degma et al. 2010*).

\section{Results}

Tardigrades were extracted from fewer than half (33 of 73) of the samples examined. Of 409 tardigrades extracted, 234 could be identified to species or speciesgroup level. As many tardigrades can be identified to species only by differences in egg morphology and few eggs were recovered from these samples, many of the specimens are identified only to subgenus or to a group of closely related species (Table 1 ). There were a minimum of 1 to a maximum of 5 species (mean 1.7) per positive sample. No tardigrades were found in 11 aquatic samples from engineered ponds, while 3 of 7 samples from Fish Creek or a natural pond yielded only a total of 5 specimens in such poor condition that they could not be readily identified (one Isohypsibius sp., two Hypsibiidae, and two other Eutardigrada).

Two species, Diphascon (subgenus Diphascon) granifer (Figure 2) and Echiniscus granulatus (Figure 3 ), are new records for Canada (Bateman and Collins 2001; Boeckner et al. 2006). Echiniscus granulatus is a widespread species found in several geographic regions (McInnes 1994), and both species have previously been recovered in North America (McInnes 1994; Bartels and Nelson 2007). Diphascon is a new genus for Alberta, represented here by both subgenera Diphascon (D. granifer and D. pingue gr.) and Adropion (D. cf. prorsirostre). Isohypsibius lunulatus, I. cf.

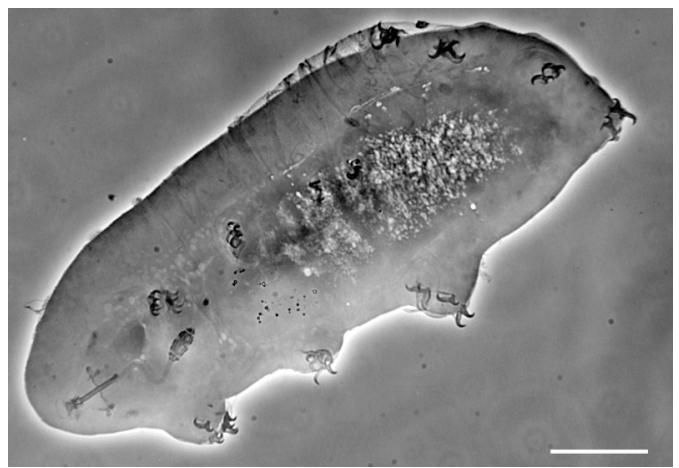

FIGURE 2. Diphascon (Diphascon) granifer beginning to shed (note duplicated claws and cuticle pulling away). Phase contrast. Scale bar $=50 \mu \mathrm{m}$.

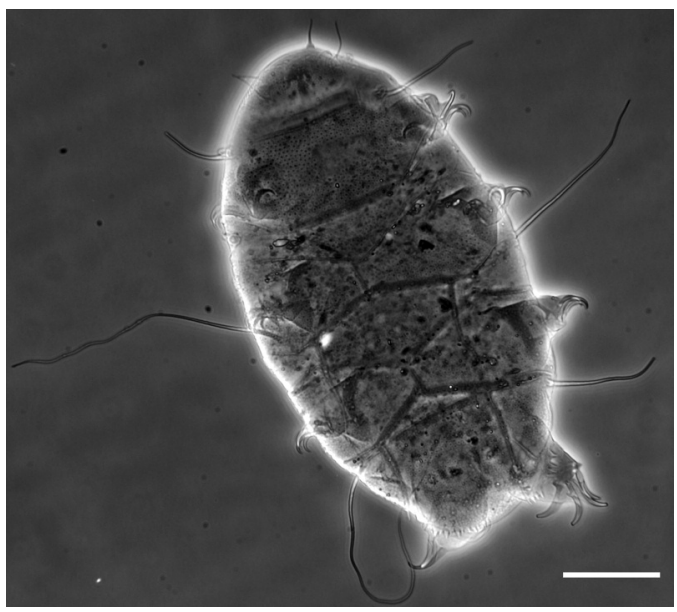

FIGURE 3. Echiniscus granulatus. Phase contrast. Scale bar $=50 \mu \mathrm{m}$. 
prosostomus, and Macrobiotus cf. harmsworthi have not previously been recorded in Alberta.

Nine of 12 lichen samples contained tardigrades, principally of the Ramazzottius oberhaeuseri group (47 individuals) and the Milnesium tardigradum group (16). Tardigrades were recovered from half of moss and litter samples (14 of 29 and 7 of 14, respectively). In moss, the Ramazzottius oberhaeuseri group (47) was most abundant, followed by Isohypsibius cf. prosostomus (40) and Isohypsibius lunulatus (25).

\section{Discussion}

In the absence of eggs, it was not possible to identify the collected Ramazzottius oberhaeuseri gr. specimens to species, but close observation suggests the presence of at least three distinct species, based on cuticular coloration and sculpture. Differences in morphology in the macroplacoids and cuticle also suggest that the specimens identified as Macrobiotus cf. harmsworthi and Paramacrobiotus cf. richtersi (listed in Boeckner et al. (2006) by its former nomenclature, Macrobiotus richtersi) may include multiple closely related species. Further collection and morphometric analysis should permit a more precise determination. Milnesium, long considered a monospecific genus, now has 14 new species described in the last two decades (Degma et al. $\left.2010^{*}\right)$. It is represented here by the species-group Milnesium tardigradum gr.

Of the examined substrates, lichen was most likely to harbour tardigrades, primarily Ramazzottius oberhaeuseri gr. and Milnesium tardigradum gr., but leaf litter had the most diverse assemblages, with a mean of 2.1 species per positive sample compared to 1.6 for lichen. The two most diverse samples, with 5 and 4 species, were both from leaf litter. This may reflect the diverse nature of leaf litter itself, which can be considered a vertical set of different microhabitats with shallow soil at the bottom. It would be worthwhile in future studies to differentiate leaf litter by the dominant type of vegetation. Trembling Aspen and White Spruce, for example, are expected to produce litter differing in numerous ways. On the other hand, moss yielded the greatest numbers of tardigrades: 20.5 per positive sample versus 8.2 for lichen and 6.1 for leaf litter.

Sample sizes were too small to make strong statements as to species distribution at present, particularly as samples from different substrates were not standardized for mass, but these figures agree generally with previous work, which has shown greater abundance and species diversity in moss and leaf litter than in lichen (Miller et al. 1996; Avdonina 2006; Bartels and Nelson 2007).

Overall, the number of tardigrades recovered was not particularly high, and many samples contained no tardigrades at all. Certainly, yields were considerably lower than those of Boeckner and Proctor (2005), who sampled moss on Black Cat Mountain in central Alber- ta. It is possible that the more urban nature of Fish Creek Provincial Park contributes to this discrepancy; it is recognized that tardigrade distribution is sensitive to, and a possible biomarker for, air quality (Moly de Peluffo et al. 2006). Fish Creek Provincial Park is a long, narrow park confined to the valley around Fish Creek. Since the Park is largely surrounded by subdivisions and is crossed by two major highways, air quality may be a factor limiting tardigrade distribution.

As expected, no tardigrades were recovered from the water of the recently created wetlands; repeat sampling in future years will be necessary to track colonization of these new environments as well as to make comparisons with similar natural wetlands in the region. It will be interesting to compare these results with observations from a wider area in southern Alberta. Based on reports of seasonality in freshwater and terrestrial tardigrades (several summarized in Kinchin 1994), it would also be useful to look for seasonal variation in tardigrade distribution while monitoring changes in the population of Fish Creek Provincial Park.

\section{Acknowledgements}

Assistance with identification was generously provided by Giovanni Pilato, Roberto Bertolani, Paul Bartels, and particularly by Diane Nelson, to whom I am much indebted. I was very fortunate to have the cheerful assistance of Caleb Cottier and Ashley Campbell for much of the collection and tardigrade isolation work. This research was generously supported by a St. Mary's University College Faculty Research and Scholarship Grant. Finally, I'm grateful to Mary Ann McLean for helpful comments on this manuscript, most notably on the ecological particulars of Fish Creek Provincial Park.

Documents Cited (marked * in text)

Degma, P., R. Bertolani, and R. Guidetti. 2010. Actual checklist of Tardigrada species (Ver. 13: 01-06-2010). Accessed 22 July 2010. http://www.tardigrada.modena .unimo.it/miscellanea/Actual\%20checklist $\% 20$ of\%20Tar digrada.pdf.

Friends of Fish Creek Provincial Park Society. 2009. Water quality monitoring report 2009. Accessed 20 March 2011. http://wsow.brbc.ab.ca/reports/FishCreekStudy2.pdf.

Friends of Fish Creek. 2010. About us. Accessed 31 July 2010. http://www.friendsoffishcreek.org/content/view/5/6/.

National Climate Data and Information Archive. 2010. Canadian climate normals 1971-2000. Environment Canada. Accessed 21 August 2010. http://climate.weatheroffice .gc.ca/climate_normals/results_e.html?StnID=2205.

\section{Literature Cited}

Anderson, R. S., and A-M. de Henau. 1980. An assessment of the meiobenthos from nine mountain lakes in western Canada. Hydrobiologia 70: 257-264.

Avdonina, A. M. 2006. Tardigrade fauna of the region between Oka and Volga rivers (Russia) and patterns of their distribution in substrates and habitats. Hydrobiologia 558: 105-109. 
Bartels, P. J., and D. R. Nelson. 2007. An evaluation of species richness estimators for tardigrades of the Great Smoky Mountains National Park, Tennessee and North Carolina, USA. Journal of Limnology 66 suppl. 1: 104-110.

Bateman, L., and M. Collins. 2001. A preliminary account of the tardigrades of Newfoundland. Zoologischer Anzeiger 240: 223-232.

Becquerel, P. 1950. La suspension de la vie au-dessous de $1 / 20 \mathrm{~K}$ absolu par démagnétisation adiabatique de l'alun de fer dans le vide le plus élevé. Comptes Rendus des Séances de 1'Académie des Sciences, Paris 231: 261-263.

Bertolani, R., R. Guidetti, K. I. Jönsson, T. Altiero, D. Boschini, and L. Rebecchi. 2004. Experiences with dormancy in tardigrades. Journal of Limnology 63 suppl. 1: $16-25$.

Boeckner, M. J., and H. C. Proctor. 2005. Water-bears from the Rocky Mountains: a first look at Alberta's tardigrade fauna. Canadian Field-Naturalist 119: 586-588.

Boeckner, M. J., M. Collins, J. Finney-Crawley, and L. Bateman. 2006. The Bryofauna of remote coastal Labrador: including a review of current Canadian records. Zootaxa 1105: 1-16.

Collins, M. 2010. Additions au groupe des tardigrades du Québec. Le Naturaliste canadien 134: 25-28.

Dastych, H. 1988. The Tardigrada of Poland. Monografie Fauny Polski 16: 1-287.

Degma, P., and R. Guidetti. 2007. Notes to the current checklist of Tardigrada. Zootaxa 1579: 41-53.

Doyère, M. L. 1842. Mémoire sur les tardigrades, II: sur la faculté que possèdent les tardigrades, les rotifères, les anguillules des toits, et quelques autres animalcules, de revenir à la vie après avoir été complètement desséchés. Annales des Sciences Naturelles, série 2, 18: 5-35.

Guidetti, R., and R. Bertolani. 2005. Tardigrade taxonomy: an updated check list of the taxa and a list of characters for their identification. Zootaxa 845: 1-46.

Hallas, T. E. 1975. A mechanical method for the extraction of Tardigrada. Memorie dell' Istituto Italiano di Idrobiologia 32 suppl.: 153-157.

Hengherr, S., M. R. Worland, A. Reuner, F. Brümmer, and R. O. Schill. 2009. Freeze tolerance, supercooling points and ice formation: comparative studies on the subzero temperature survival of limno-terrestrial tardigrades. Journal of Experimental Biology 212: 802-807.

Hohberg, K. 2006. Tardigrade species composition in young soils and some aspects on life history of Macrobiotus richtersi J. Murray, 1911. Pedobiologia 50: 267-274.

Jönsson, K. I., and R. Bertolani. 2001. Facts and fiction about long-term survival in tardigrades. Journal of Zoology 255: 121-123.
Jönsson, K. I., E. Rabbow, R. O. Schill, M. Harms-Ringdahl, and P. Rettberg. 2008. Tardigrades survive exposure to space in low Earth orbit. Current Biology 18: 729-731.

Kinchin, I. M. 1994. The Biology of Tardigrades. Portland Press, London. 186 pages.

May, R. M., M. Maria, and J. Guimard. 1964. Actions différentielles des rayons $\mathrm{x}$ et ultraviolets sur le tardigrade Macrobiotus areolatus, à 1 état actif et desséché. Bulletin biologique de la France et de la Belgique 98: 349-367. Quoted in Bertolani et al. (2004), 16.

McInnes, S. J. 1994. Zoogeographic distribution of terrestrial/ freshwater tardigrades from current literature. Journal of Natural History 28: 257-352.

Miller, W. R., J. D. Miller, and H. Heatwole. 1996. Tardigrades of the Australian Antarctic Territories: the Windmill Islands, East Antarctica. Zoological Journal of the Linnean Society 116: 175-184.

Moly de Peluffo, M. C., J. R. Peluffo, A. M. Rocha, and I. L. Doma. 2006. Tardigrade distribution in a medium-sized city of central Argentina. Hydrobiologia 558: 141-150.

Nelson, D. R., R. Guidetti, and L. Rebecchi. 2009. Tardigrada. Pages 455-484 in Ecology and Classification of North American Freshwater Invertebrates. Edited by J. H. Thorp and A. P. Covich. Third edition. Academic Press, San Diego, California.

Pilato, G., and M. G. Binda. 2001. Biogeography and limno-terrestrial tardigrades: are they truly incompatible binomials? Zoologischer Anzeiger 240: 511-516.

Pilato, G., and M. G. Binda. 2010. Definition of families, subfamilies, genera and subgenera of the Eutardigrada, and keys to their identification. Zootaxa 2404: 1-54.

Pinel, H. W. 1980. Pages 197-283 in Calgary's Natural Areas: a report prepared by the Natural Areas Committee of the Calgary Field Naturalists Society, December 1980. Calgary Field Naturalists Society, Calgary, Alberta.

Rahm, P. G. 1921. Biologische und physiologische Beiträge zur Kenntnis der Moosfauna. Zeitschrift für allgemeine Physiologie 20: 1-34. Quoted in Bertolani et al. (2004), 16.

Ramazzotti, G., and W. Maucci. 1983. Il phylum Tardigrada (III edizione riveduta e aggiornata). English translation by C. W. Beasley, 1995. Memorie dell' Istituto Italiano di Idrobiologia 41: 1-1012.

Robertson, A. 1991. A guide to Fish Creek Provincial Park. Rocky Mountain Books, Calgary, Alberta. 128 pages.

Seki, K., and J. Toyoshima. 1998. Preserving tardigrades under pressure. Nature 395: 853-854.

Uhía, E., and M. J. I. Briones. 2002. Population dynamics and vertical distribution of enchytraeids and tardigrades in response to deforestation. Acta Oecologica 23: 349-359.

Received 27 August 2010

Accepted 29 October 2010 